NBER WORKING PAPER SERIES

INTERACTIONS BETWEEN STATE AND FEDERAL CLIMATE CHANGE POLICIES

Lawrence H. Goulder

Robert N. Stavins

Working Paper 16123

http://www.nber.org/papers/w16123

\author{
NATIONAL BUREAU OF ECONOMIC RESEARCH \\ 1050 Massachusetts Avenue \\ Cambridge, MA 02138 \\ June 2010
}

The authors are grateful to Dallas Burtraw, Anthony Eggert, Arik Levinson, and Catherine Wolfram for helpful comments on a previous version of this chapter. The views expressed herein are those of the authors and do not necessarily reflect the views of the National Bureau of Economic Research.

NBER working papers are circulated for discussion and comment purposes. They have not been peerreviewed or been subject to the review by the NBER Board of Directors that accompanies official NBER publications.

(C) 2010 by Lawrence H. Goulder and Robert N. Stavins. All rights reserved. Short sections of text, not to exceed two paragraphs, may be quoted without explicit permission provided that full credit, including $\odot$ notice, is given to the source. 
Interactions between State and Federal Climate Change Policies

Lawrence H. Goulder and Robert N. Stavins

NBER Working Paper No. 16123

June 2010

JEL No. H10,H77,K32,L51,Q48,Q54

\begin{abstract}
$\underline{\text { ABSTRACT }}$
Federal action addressing climate change is likely to emerge either through new legislation or via the U.S. EPA's authority under the Clean Air Act. The prospect of federal action raises important questions regarding the interconnections between federal efforts and state-level climate policy developments. In the presence of federal policies, to what extent will state efforts be cost-effective? How does the co-existence of state- and federal-level policies affect the ability of state efforts to achieve emissions reductions?

This paper addresses these questions. We find that state-level policy in the presence of a federal policy can be beneficial or problematic, depending on the nature of the overlap between the two systems, the relative stringency of the efforts, and the types of policy instruments engaged. When the federal policy sets limits on aggregate emissions quantities, or allows manufacturers or facilities to average performance across states, the emission reductions accomplished by a subset of U.S. states may reduce pressure on the constraints posed by the federal policy, thereby freeing facilities or manufacturers to increase emissions in other states. This leads to serious "emissions leakage" and a loss of cost-effectiveness at the national level. In contrast, when the federal policy sets prices for emissions or does not allow manufactures to average performance across states, these difficulties are usually avoided. Even in circumstances involving problematic interactions, there may be other attractions of state-level climate policy. We evaluate a number of arguments that have been made to support state-level climate policy in the presence of federal policies, even when problematic interactions arise.
\end{abstract}

Lawrence H. Goulder

Department of Economics

Landau Economics Building 328

Stanford University

Stanford, CA 94305

and NBER

goulder@stanford.edu

Robert N. Stavins

JFK School of Government

Harvard University

79 JFK Street

Cambridge, MA 02138

and NBER

robert_stavins@harvard.edu 


\title{
Interactions between State and Federal Climate Change Policies
}

\author{
Lawrence H. Goulder and Robert N. Stavins
}

\section{Introduction}

Over the past five years, a series of climate bills with national cap-and-trade systems at their heart have been introduced in the U.S. Congress. But as of June 2010, only one bill - H.R. 2454, the American Clean Energy and Security Act of 2009 - had been passed by a house of Congress, and no bill had been sent to the President for his signature. In this environment of relatively slow federal action, climate policy initiatives have emerged at the regional, state, and even local levels. In fact, state-level climate policies are being contemplated, developed, or implemented in more than half of the fifty states. ${ }^{1,2}$

Federal-level action may soon take place, however. This could come through Congressional action or through greenhouse gas regulation by the U.S Environmental Protection Agency under the Clean Air Act. In the absence of Congressional action, EPA action is called for as a result of the 2006 U.S. Supreme Court decision in Massachusetts $v . E P A,{ }^{3}$ the Obama administration's subsequent "endangerment finding” that carbon dioxide (and other greenhouse gases) endanger public health and welfare, and the consequent designation in 2010 of carbon dioxide as a pollutant for regulatory purposes under the Clean Air Act both for stationary and mobile sources.

No matter whether federal action comes through new legislation or via the EPA's authority under the Clean Air Act, important questions arise regarding the relationship of federal actions to ongoing state-level climate policy developments. In the presence of federal policies, to what extent will state efforts be cost-effective? How does the co-existence of state- and federallevel policies affect the ability of state efforts to achieve emissions reductions?

This chapter addresses these questions. We find that the co-existence of state and federal climate efforts can be mutually reinforcing or problematic, depending on the nature of the overlap between the two systems, the relative stringency of the efforts, and the types of policy instruments utilized. Problematic interactions arise when the federal policy involves restrictions on aggregate

\footnotetext{
${ }^{1}$ Most prominent among these are the Regional Greenhouse Gas Initiative (RGGI) in ten northeastern states, and A.B. 32, California’s Global Warming Solutions Act of 2006.

${ }^{2}$ Throughout most of U.S. history, state and local governments have had the primary responsibility for environmental protection (Revesz 2001). However, since the passage of the National Environmental Policy Act in 1969, the federal role has increased significantly. Federal laws for localized environmental problems generally leave room for states to exceed national standards.

${ }^{3}$ See: http://www.supremecourt.gov/opinions/06pdf/05-1120.pdf
} 
emissions quantities (as with a simple federal cap-and-trade program) or involves nationwide averaging of performance (as with fuel-economy standards or renewable fuel standards). In these circumstances, the emission reductions accomplished by a subset of U.S. states reduces pressure on the constraints posed by the federal policy, thereby freeing - indeed, encouraging - facilities or manufacturers to increase emissions in other states. This leads to "emissions leakage" and a loss of cost-effectiveness at the national level. In contrast, when the federal policy fixes prices for emissions (as under carbon taxes or under a cap-and-trade program with a binding "safety valve" or "price collar"), more aggressive climate policy in a subset of states does not lead to offsetting emissions elsewhere. Nationwide emissions are reduced, but the more aggressive action generally leads to differing marginal abatement costs across states, implying that the same reduction could have been achieved at lower cost though an increase in the federally established price of emissions.

Even in situations where significant leakage is likely, there may be a case for state-level action to the extent that such action yields other, offsetting benefits. We articulate and evaluate a number of arguments that claim such benefits and are raised to support state-level climate policy in the presence of federal policies, despite the potential for leakage.

The chapter is organized as follows. Section 2 examines interactions between federal and state cap-and-trade programs, while Section 3 examines interactions under other policies, including fuel economy standards and renewable fuel standards. In both of these sections, we highlight difficulties that stem from these interactions, and explore the extent to which avoiding these problems is consistent with the continuing presence of state programs. Section 4 evaluates several arguments claiming various benefits from state-level action that may offset the disadvantages (such as emissions leakage) identified earlier. Section 5 concludes.

\section{National and Sub-National Cap-and-Trade Systems}

How would a federal cap-and-trade system interact with one or more state (or other subnational) cap-and-trade systems? Two key factors driving such interactions are the degree of overlap in coverage (scope of sources) between the federal and state systems, and the relative stringency of the two systems. We consider two important cases: programs with perfectly overlapping coverage, and programs with imperfectly overlapping coverage. ${ }^{4}$

\subsection{Systems with Perfectly Overlapping Coverage}

The simplest case is systems with perfectly overlapping coverage. One example is the case involving upstream federal and state cap-and-trade systems, both of which are economy-wide. Another is the case in which the federal and state systems both focus exclusively on the electricity generation sector.

\footnotetext{
${ }^{4}$ Although our focus is on impacts of overlapping regulations across jurisdictions, the analysis has some formal similarities to the analysis of outcomes from overlapping regulations within a jurisdiction. Levinson (this volume) offers the latter analysis.
} 
Consider first the situation where the state program is more stringent than the national program in that it requires reductions from sources within the state that are greater than would be achieved under the national program alone. In this case, emissions sources must surrender both state and federal allowances to comply with the two jurisdictions. If a source only needed to surrender to one jurisdiction, it would choose abatement levels such that marginal abatement costs equaled the allowance price. If the source must offer allowances to two jurisdictions, it will equate marginal abatement costs with the sum of the two allowance prices.

Figure 1 below depicts the impact of facing two allowance prices. The figure displays marginal benefits from emissions (corresponding to marginal costs of emissions abatement) for two groups of states; the "greener states" prefer more stringent cap-and-trade policy than the other states do. Suppose that initially the only cap-and-trade program is at the federal level. With allowance trading across all states, marginal abatement costs are equated across states, and a single allowance price of $p_{F E D}$ applies nationwide. Total emissions at the national level are $e_{G S}$ plus $e_{O S}$, a total given by the federal policy’s overall emissions cap.

Now suppose the greener states wish to impose a tighter cap-and-trade program within their own jurisdictions. They establish their own allowance cap of $e_{G S}$ ', allowing fewer emissions than their prior equilibrium emissions level $e_{G s}$. The tighter cap compels producers in the greener states to reduce their emissions further. This reduces demands for the federal level allowances, causing the price of these allowances to fall, which leads to increased emissions in the other states. The new equilibrium price of federal allowances is $p_{F E D}$ '. The price of the green states' allowances is $p_{G S}$, determined such that the sum of the federal allowance price and the state allowance price equals the green states' marginal costs of abatement at $e_{G S}$ '.

Importantly, the greener states' efforts do not lead to any reductions in national emissions beyond that mandated by the federal cap. These states face marginal abatement costs of is $p_{F E D}$ ' plus $p_{G S}$, higher than those $\left(p_{F E D}\right.$ ') in the other states. With marginal costs not equalized nationally, the country's overall abatement costs are greater than under the federal program alone. 5 Thus, the presence of the greener states’ program compromises cost-effectiveness.

This is the likely outcome from the interaction of a stringent California cap-and-trade system implemented under AB 32 and a less stringent federal system (assuming similar coverage). California's tighter cap would not achieve any further reductions in emissions. At the same time it would add to the state's costs and to the nationwide costs of achieving the national target.

\footnotetext{
${ }^{5}$ Prior analyses by McGuinness and Ellerman (2008) and Burtraw and Shobe (2009) offered similar results.
} 
What would happen if the state program were less stringent than the federal program in the sense of requiring smaller reductions from sources within the state than would be achieved under the Federal program alone? This would be a case where the greener states' cap is to the right of $e_{G s}$. In this case, the federal allowance price would be sufficiently high to cause sources in the state to reduce emissions below the state cap; the state's cap is therefore not binding and the equilibrium price of state allowances is zero. Here the state program has no impact - it neither affects nationwide nor in-state emissions nor alters the cost-effectiveness of the federal program.

\subsection{Systems with Imperfectly Overlapping Coverage}

Now consider the case where the national and state programs involve imperfectly overlapping coverage. In this case, the nature of the interaction again depends upon which program is more comprehensive in its coverage of state sources. It also depends on which program is more stringent for the sources covered by both programs.

If the scope of the federal program envelops that of the state program (that is, includes all the sources in the state program plus others), then for those sectors covered by both the national and the state program, the results are the same as with perfectly overlapping coverage. If the state program is more stringent, the same leakage problems and losses of cost-effectiveness apply as previously discussed. If the state program is less stringent, then it has no impact. This is essentially the case with the Regional Greenhouse Gas Initiative (RGGI) in the northeast, which covers only the electricity sector and is considerably less stringent than the major proposals for national economy-wide cap-and-trade systems.

If the state program is more comprehensive than the federal program, results again depend on relative stringency. If the state program is more stringent (for the common covered sectors) than the federal program, then the federal program becomes irrelevant as regards emissions within the state involved. In this case, the more stringent state program will loosen pressure on the federal cap, leading to a reduction in federal allowance prices and associated emissions leakage to other states. If the state program is less stringent for the common covered sectors, reductions in common-covered sector in the state will be governed by the federal program. In this case, the state policy has no direct impact on federal allowance prices and thus generates no leakage to other states. In both of these cases, the state can bring about reductions in nationwide emissions by causing reductions in sectors not covered by the federal program.

\subsection{Other Design Features and Their Implications}

How do other design features affect the nature of interaction of state and federal cap-andtrade systems?

Safety Valves. Some proposals for cap and trade include provisions for a "safety valve" or ceiling price on allowances. When a safety valve provision is included, the regulating authority prevents allowance prices from exceeding a given level by issuing additional emissions allowances as necessary. The effect of a safety valve depends on whether and how often it is triggered. Consider, for example, a scenario involving perfectly overlapping state and federal systems, and suppose that initially a safety valve in the federal system is active, so that allowance prices are at 
the ceiling price. Suppose that the level of emissions in a given state is $e_{1}$ in equilibrium in this situation. Now consider what happens if this state attempts to cap its own emissions below $e_{1}$. The given state's tighter cap will force additional abatement in that state, raising its marginal and total abatement costs.

The impact of the state's actions on nationwide emissions depends on whether the actions produce a large enough reduction in demand for federal allowances to disengage the safety valve. If the state's reduction is too small to disengage the safety valve, then the price of federal allowances will be unchanged: it will remain at the ceiling price. In this case, the state's actions will imply a reduction in the nation's overall emissions, since the state's own emissions reduction will not be accompanied by any increase in emissions in other states (the price of allowances to other states has not changed). On the other hand, if the given state's reduction yields a large enough reduction in demand for federal allowances to disengage the safety valve, then the price of federal allowances will fall, thereby inducing an offsetting increase in emissions from other states.

Allowance Allocation Methods. The nature of the allowance allocation in general has no affect on system interaction (although there are exceptions in the case of regulated industries). The interactions just described will be the same no matter how much one or both programs relies on auctioning or free allocation. Although the particular allowance allocation method has important distributional implications and can affect cost-effectiveness as well, it does not alter the general pattern of state-federal interactions just described. ${ }^{6}$ This is in keeping with the fact that the allowance allocation method generally does not alter incentives at the margin (or allowance prices); and it is the marginal incentives that determine emissions levels and cost-effectiveness.

\section{$2.4 \quad$ Potential Resolutions}

A Carve Out. There are ways to offset or avoid the leakage that would occur in the problematic cases above. One is for the federal government to allow a state or group of states a "carve out" from the federal program if they implement or maintain a state program (or state programs) at least as stringent. In this case, two disjoint cap-and-trade programs emerge: the federal system applies only to states that do not carve out. The result is that there will be different allowance prices in some states and in the Federal system, marginal abatement costs will not be equated, and so cost-effectiveness will not be achieved.

Re-Denominating Federal Allowances. Another option is for a given state to require covered facilities with the state to submit more federal allowances per unit of emissions than would ordinarily be the case. This action by a "greener" state does not eliminate leakage, since it increases the effective price of reducing emissions in this state relative to the price in other states. However, in this case leakage is less than 100 percent: the state's action has the effect of tightening the national cap, since the given number of federal allowances in circulation now permits fewer nationwide emissions, assuming some emissions continue in the "greener" state.

\footnotetext{
${ }^{6}$ Regulated firms generally face lower costs if they receive allowances free rather than need to purchase them in an auction. (See, for example, Bovenberg and Goulder, 2001.) In addition, to the extent that allowances are auctioned and the proceeds are used to finance reductions in distortionary taxes, policy costs will be lower than in cases involving other uses of auction revenue or in the case of free allocation. (See, for example, Goulder, Parry, Williams, and Burtraw, 1999.)
} 
Pre-Emption. Another way to avoid problematic interactions is through federal rules preempting (that is, barring) state-level cap and trade in the presence of a federal program. Some consider this a useful method for preventing leakage and a loss of cost-effectiveness, as well as a way of assuring that private industry does not face multiple performance or technology standards. Others point out that to the extent that the greener state's actions raise costs, those costs are borne by that state alone; correspondingly, they oppose pre-emption on the grounds that states should have the freedom to decide whether to impose higher costs on themselves.

\section{Interactions under Other Climate Policies}

\subsection{Fuel-Economy Standards}

Problematic interactions can also occur under policies involving automobile fuel-efficiency standards or limits on automobiles' greenhouse gas emissions per mile. In response to the prospect of climate change, fourteen states moved to establish limits on greenhouse gases (GHGs) per mile from light-duty automobiles. These so-called "Pavley" standards ${ }^{7}$ require manufacturers to reduce per-mile GHG emissions by about 30 percent by 2016 and 45 percent by 2020 (California Air Resources Board, 2008)

Since $\mathrm{CO}_{2}$ emissions and gasoline use are nearly proportional, the Pavley limits effectively raise the fuel economy requirements for manufacturers in the states adopting such limits. These state-level actions can interact significantly with the existing federal Corporate Average Fuel Economy (CAFE) standards. Consider an auto manufacturer that prior to the imposition of the Pavley limits was just meeting the federal CAFE standard. Now it must meet the (tougher) Pavley requirement through its sales of cars registered in the adopting states. In meeting the tougher Pavley requirements, its overall U.S. average fuel economy now exceeds the national requirement: the national constraint no longer binds. This means that the manufacturer is now able to change the composition of its sales outside of the Pavley states; specifically, it can shift its sales toward larger cars with lower fuel-economy.

Indeed, if all manufacturers were initially constrained by the national CAFE standard, the introduction of the Pavley requirements would lead to "emissions leakage” of 100 percent at the margin, because the reductions within the Pavley states would be completely offset by emissions increases outside of those states. Using a numerical simulation model of the U.S. automobile market, Goulder, Jacobsen, and van Benthem (2009) found that from 2009 through 2020 about 65 percent of the emissions reductions achieved in the new car market in the Pavley states would be offset by increased emissions in new car markets elsewhere. ${ }^{8}$

\footnotetext{
${ }^{7}$ The Pavley standards are named after California Assemblywoman Fran Pavley, who sponsored the California bill that launched this multi-state effort.

${ }^{8}$ Another five percent of the emissions reduction is offset by increased emissions from used cars, as the Pavley effort leads to lower scrap rates of older, less fuel-efficient automobiles.
} 
In May 2009, the Obama administration reached an agreement with the fourteen "Pavley states," according to which the U.S. would tighten the federal fuel economy requirements in such a way as to achieve effective reductions in GHGs per mile consistent with the first-phase goals of the Pavley initiative. In return, the fourteen states agreed to abandon the first phase of the Pavley effort, which was no longer necessary, given the tightening of the federal standards. However, these states still intend to introduce further tightening of the greenhouse-gas-per-mile standards after 2016. This would imply fuel economy standards more stringent than those applying at the federal level. Hence the leakage issue remains live. ${ }^{9}$

\subsection{Renewable Fuel and Portfolio Standards}

Renewable fuel standards require that the ratio of renewable to conventional fuels produced by refiners not fall below a given value. When these standard are imposed at both the state and federal levels, once again the effort of individual states to exceed the federal standard could fail to bring about reduced emissions (or increased use of renewable fuels). ${ }^{10}$

This will be the case if, to meet the federal requirement, firms can apply a ratio based on overall (nationwide) use of renewable and conventional fuels. In this case the situation is perfectly analogous to that described above for fuel-economy standards. If a firm's ratio of renewable to refined fuels was just high enough to meet the federal requirement, then when a given state imposes a higher ratio, the firm will more than meet the federal requirement. It is now able to utilize more conventional fuels in other states in which it operates. On other hand, if the federal rules require that each refinery operation - as opposed to each refinery company -- meet the given ratio, the situation is different. In this case tighter requirements imposed by a given state will not free up firms to make compensating adjustments in other states.

The same interactions and pattern of outcomes would hold in the case of federal and statelevel renewable portfolio standards, which require the electrical generators utilize renewable sources of energy (in particular, wind and solar) for a specific share of their annual generation. The federal systems contemplated in Washington would allow for national trading.

\subsection{Interactions When the Federal and State Programs Involve Different Instruments}

Significant interactions can also occur when the state and federal climate policy instruments differ. As mentioned in the introduction, federal climate policy might be undertaken

\footnotetext{
${ }^{9}$ Despite the potential for leakage, the tougher state-level standards may conceivably accelerate the development of new technologies that auto manufacturers will eventually adopt throughout the nation, thereby leading to lower emissions and reduced fuel consumption. However, Goulder, Jacobsen, and van Benthem (2009) find that in the presence of the national CAFE standard, faster technological progress exacerbates the adverse fleet compositional impacts of state programs. As a result, in this context greater technological progress yields relatively little benefit in terms of reduced fuel consumption.

${ }^{10}$ Apart from the leakage issue discussed here, some analyses indicate that a renewable fuel standard may have significant disadvantages relative to emissions pricing policies such as carbon taxes or cap and trade. Holland, Hughes and Knittel (2009) show that the renewable fuel standard effectively subsidizes renewable fuels and that, as a result, it leads to more overall (renewable plus conventional) fuel use than is economically efficient. See also Wolak (2007).
} 
by the U.S. EPA under the auspices of the Clean Air Act. In this event, the EPA would probably make use of "conventional" regulatory approaches such as performance standards and technology mandates. Yet cap and trade is likely to continue in the northeast under the Regional Greenhouse Gas Initiative, and many western states plan to implement cap and trade within the next few years. How would conventional regulation at the federal level interact with the state-level cap-and-trade programs?

Much depends on the particular instruments employed at the federal level and on the specific rules governing the use of these instruments. Consider the following plausible scenario. Suppose that the EPA imposes performance standards such as limits on emissions of certain greenhouse gases per unit of output. State- or regional-level cap-and-trade programs will induce changes in producer behavior, and in some cases these adjustment will cause particular facilities to exceed the federal performance standard. If the federal rules allow firms (or localities) to average their emissions-output ratios in determining whether they meet the federal standard, then the capand-trade initiatives at the state or regional level will precipitate offsetting adjustments in other states or regions. The same applies if the federal rules allow firms or localities to trade performance credits with one another. ${ }^{11}$ Thus, the specifics of the federal rules are important.

\subsection{Problematic Circumstances and Benign Cases}

Thus, the potential for leakage and the associated loss of cost-effectiveness arise under a variety of circumstances. In general, problems result when both of the following two conditions apply: (1) the state-level efforts cause firms or facilities within the greener states to overcomply with the federal rules and, (2) the federal rules give firms or facilities the freedom to offset this overcompliance through various adjustments in other states.

We have already noted some cases where the two problematic conditions do not apply. One is when there is no overlap of the federal and state programs (condition 1 is not met). Another is when performance standards do not involve nationwide averaging (condition 2 is not met).

Another circumstance where problems are avoided is when the federal-level program sets prices. (This case was suggested by the Section 2.3's discussion of a safety valve.) Suppose, for example, a carbon tax were imposed at the federal level. If a state decided to impose new regulations requiring in-state reductions beyond what the federal tax would yield, the additional state-level reductions would not lead to offsetting increases elsewhere (apart from the usual "economic leakage"): the reductions in other states would remain governed by the federal carbon tax. Thus, price-based regulation at the federal level can avoid the problematic state-federal interactions. However, to the extent that the new state regulations imply differing marginal abatement costs across states, there is potential exists for achieving the same further reduction in emissions at lower cost through a higher carbon tax.

\footnotetext{
${ }^{11}$ Some instruments are more conducive to averaging or cross-facility trading than others. Trading or averaging is relatively straightforward with performance standards, but more difficult with technology mandates.
} 


\section{Are There Other, Offsetting Benefits from State-Level Action?}

Even in situations where significant leakage is likely, there may be a case for state-level action to the extent that such action yields other benefits. Here we assess a number of such arguments.

\subsection{Stronger Arguments}

We first present arguments that we regard as having some validity, although some require careful qualification.

- States can contribute to cost-effectiveness by addressing market failures not addressed by federal climate policy.

In addition to the environmental externality associated with climate change, there are some other market failures that merit attention. The presence of these other market failures would imply that getting relative prices right will not - on its own -- yield the most efficient outcome. To the degree that federal climate policy disregards these other climate-related market failures, the potential exists for states to promote greater efficiency by addressing the neglected market failures.

States (and, for that matter, localities) may have an advantage over the federal government in addressing certain other market failures. For example, they may be most capable of dealing with the failure stemming from the principal-agent problem associated with renter-occupied buildings, according to which apartment renters have insufficient incentives to conserve electricity. States, counties, and cities can productively promote energy efficiency by addressing this market failure through building codes and zoning (Trisolini 2010). Note, however, that in some cases the additional market failure is most efficiently addressed through federal policy.

- States can function as test-beds for alternative policy approaches not contained in an existing federal effort, thereby providing useful information for possible later adoption at the federal level.

Clearly, experimentation has appeal, since experiments sometimes pay off handsomely (Ostrom 2009). Note that this argument seems to call for eventual implementation of the innovative policy approach at the federal level and a phasing-out of this effort at the state level after the benefits from given experiments are revealed. Note also that the question arises whether the experimentation is best carried out at the state, as opposed to federal, level.

- State policies - particularly those that are more stringent than the federal policy - can exert pressure for more aggressive action at the federal level if the state efforts appear effective.

To the extent that a state with more aggressive climate policy can demonstrate that greater reductions can be achieved at lower cost than previously thought, this can give impetus to stronger 
federal policy. Here again the state is functioning as a test bed, providing new information. In the previous case, the new information comes from an experimental policy design; in this case it comes from the revealed impact of a more stringent policy.

- When a given state imposes a tougher requirement than applies in other states, it can pressure manufacturers to adopt the tighter requirement nationwide rather than offer different technologies in different parts of the country.

California's tighter auto pollution laws in the 1970s led to the tightening of the federal auto pollution standards - in part because auto manufacturers did not want to face two standards. Likewise, the Pavley effort initiated by California may have been instrumental in prompting the Obama administration's agreement to tighten federal fuel economy standards. Of course, in neither case does such causality imply that social welfare is maximized by the more stringent standard being adopted nationally.

\subsection{Weaker Arguments}

The following arguments seem to have considerably less merit.

- States may face different costs of achieving greenhouse gas reductions, and may experience different benefits from avoided climate change (either because of different preferences or different physical outcomes)

Differences of this sort exist and are important, but such differences do not provide a sound justification for state-level policy. Instead, they may justify compensation schemes and other elements that allow for differential net burdens across states, such as through the allocation across states of allowances or auction revenues from a federal cap-and-trade system

- States are more familiar with details related to in-state firms and institutions. With this better information, they may be most capable of exploiting low-cost opportunities for addressing climate change.

Clearly, federal regulators - and state regulators as well -- have limited information. Individual firms tend to have much better information about technological opportunities and abatement costs than do regulators. The information problem primarily provides a sound argument for market-based environmental policy - for policy approaches that give individual facilities or firms the flexibility to make best use of their (better) information. Market-based policies such as cap-and-trade or carbon taxes have this feature. Note that such policies can address the information problem effectively, even if the policies are introduced at the federal level. Thus, this information problem does not provide a good reason for state-level policy.

\section{Conclusions}

We have examined the nature and impacts of some important interactions between state and federal climate policy. Depending on the overlap and stringency of the state and federal 
policies, as well as the types of policy instruments employed, state efforts in the presence of a federal policy can be useful or counterproductive.

In general, problems result when both of the following two conditions apply: (1) the statelevel efforts cause firms or facilities within the greener states to overcomply with the federal rules; and (2) the federal rules give firms or facilities the freedom to offset this overcompliance through various adjustments in other states. In these circumstances, state-level efforts do not succeed in reducing greenhouse gas emissions nationally, and they reduce the cost-effectiveness of the overall national effort.

We find that there is more potential for these difficulties when the federal policy sets limits on aggregate emissions quantities, or allows manufacturers or facilities to average performance across states. In contrast, the difficulties are usually avoided when the policies have little overlap or when the federal policy sets prices for emissions.

Even in circumstances involving problematic interactions, there may be offsetting attractions of state-level climate policy. We evaluated a number of arguments that have been made to support state-level climate policy in the presence of federal policies, even when problematic interactions arise, and found some arguments - with caveats - to be compelling, but others much less so. 


\section{REFERENCES}

Bovenberg, A. Lans, and Lawrence H. Goulder. "Neutralizing the Adverse Industry Impacts of CO2 Abatement Policies: What Does It Cost?” Behavioral and Distributional Effects of Environmental Policy, C. Carraro and G. Metcalf, eds., University of Chicago Press, 2001.

Burtraw, Dallas, and Bill Shobe. "State and Local Climate Policy under a National Emissions Floor.” Working paper, Resources for the Future and University of Virginia, March 2009.

California Air Resources Board. The California Global Warming Solutions Act of 2006. Text of Assembly Bill 32, August 31, 2006. http://www.arb.ca.gov/cc/docs/ab32text.pdf

California Air Resources Board. “Comparison of Greenhouse Gas Reductions for the United States and Canada under U.S. CAFE Standards and California Air Resources Board Regulations: An Enhanced Technical Assessment,” 2008. Available at http://www.climatechange.ca.gov/publications/arb.html.

Goulder, Lawrence H., Ian W. H. Parry, Roberton C. Williams III, and Dallas Burtraw. "The Cost-Effectiveness of Alternative Instruments for Environmental Protection in a Second-best Setting." Journal of Public Economics 72(3):329-60, 1999.

Goulder, Lawrence H., Mark R. Jacobsen, and Arthur van Benthem. "Unintended Consequences from Nested State and Federal Regulations: The Case of the Pavley Greenhouse-Gas-per-Mile Limits.” Working paper, Stanford University and University of California, San Diego. August 2009.

Holland, Stephen P., Jonathan E. Hughes, and Christopher R. Knittel. "Greenhouse Gas Reductions under Low Carbon Fuel Standards?” American Economic Journal: Economic Policy 1(1): 106-46, 2009.

Levinson, Arik. “Interactions among Climate Policy Regulations.” This volume.

McGuinness, Meghan and A. Denny Ellerman. The Effects of Interactions between Federal and State Climate Policies. CEEPR 08-004. Cambridge, MA: Massachusetts Institute of Technology Center for Energy and Environmental Policy Research, May 2008.

Ostrom, Elinor. “A Polycentric Approach for Coping with Climate Change.” Policy Research Work Paper 5095. Washington, D.C.: The World Bank, October 2009.

Revesz, Richard L. AFederalism and Environmental Regulation: A Public Choice Analysis.@ Harvard Law Review (2001), volume 111, pp. 553-641. 
Trisolini, Katherine A. "All Hands on Deck: Local Governments and the Potential for Bidirectional Climate Change Regulation.” Stanford Law Review, volume 62, issue 3, 2010, pp. 669-746.

Wolak, Frank. “Low-Carbon Fuel Standards: Do They Really Work?” Stanford Institute for Economic Policy Research Policy Brief, May. 
Figure 1: Interaction of Federal and State Cap-and-Trade Programs

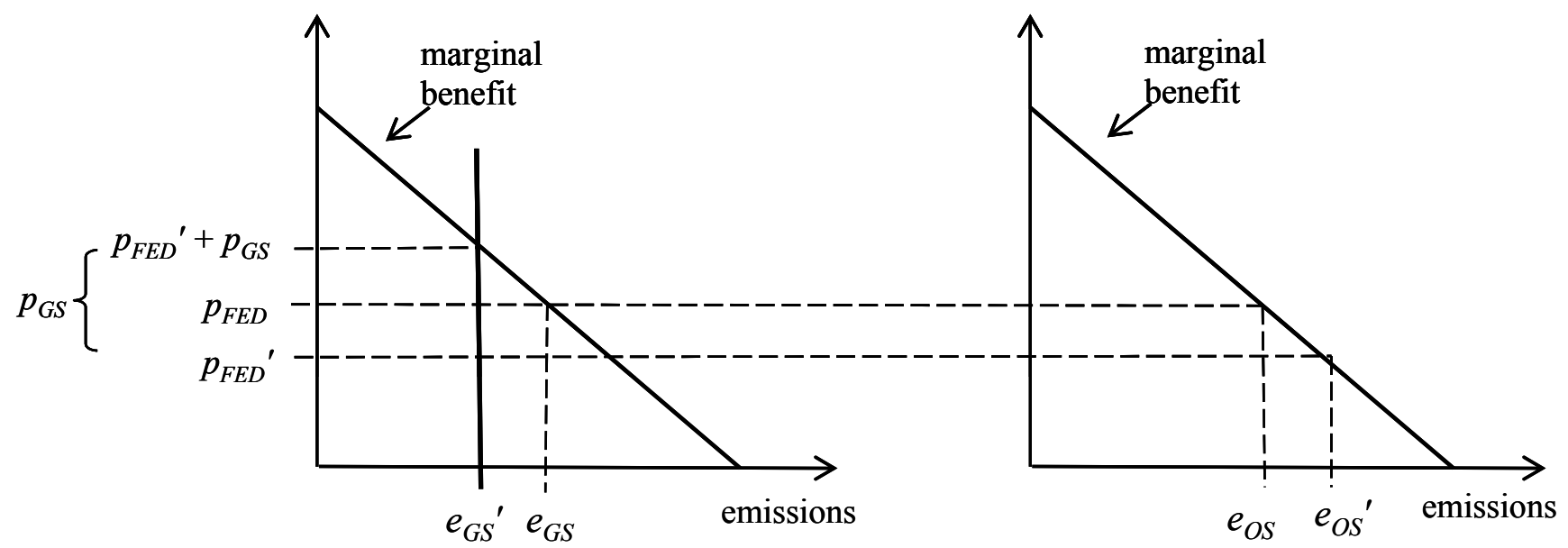

Greener States

Other States 